\title{
Эпохи корообразования в кайнозое Воронежской антеклизы
}

\author{
(2020 Д. А. Дмитриев ${ }^{\bowtie}$, А. В. Жабин, В. А. Свиридов \\ ${ }^{1}$ Воронежский государственный университет, \\ Университетская пл., 1, 394018, Воронеж, Российская Федерация
}

\begin{abstract}
Аннотация
Введение: Кайнозойские образования Воронежской антеклизы, мощностью до 100 м, доступны для исследования в обнажениях на склонах речных долин, балок, оврагов и керну неглубоких скважин. Они представлены песчано-глинистыми породами различного генезиса. Для палеогена характерны морские отложения, неогена - аллювиальные и озерные. Четвертичные образования, наиболее представительные по генетическим типам пород, сложены аллювиальными, речными террасовыми, ледниковыми отложениями и покровными суглинками. В истории кайнозоя Воронежской антеклизы выделяются три эпохи корообразования - палеоценовая, олигоцен-миоценовая и позднечетвертичная. С отложениями каждой из них связаны определённые полезные ископаемые. Наиболее ценное - кремнисто-цеолитное сырьё приурочено к последней из них. В статье обсуждаются вопросы связи климата, рельефа поверхности, типа пород с минеральным составом кор выветривания. Даётся генетическая интерпретация образования минералов в гипергенных процесcax.

Методика: Исследование минерального состава пород, составляющих как самих кор выветривания, так и вмещающих их отложений проводилось рентгеноструктурным и электронномикроскопическим методами анализа.

Результаты $и$ обсуждение: Палеоценовая эпоха представлена корой выветривания линейноплощадного типа, залегающей на закарстованной поверхности отложений верхнего мела. Её формирование происходило в условиях тёплого и влажного субтропического климата (не исключено, что и тропического, по наличию гиббсита в некоторых разрезах). Олигоцен-миоценовая - выявляется по «зрелым» коррелятным породам в верхах олигоцена и низах миоцена, представленных континентальной шапкинской толщей. Каолинитовый состав её нижней части и монтмориллонитовой - верхней, представляют как бы перевернутый разрез коры выветривания. Её формирование проходило в менее благоприятном для выветривания климате из-за меньших температур и влажности, что выразилось в сокращении мощности элювия. В позднечетвертичную эпоху на рассматриваемой территории формировался современный рельеф в условиях умеренного климата. На легко разлагающихся мел-мергельных породах образовалась своеобразная кремнистая КВ, широко развитая под четвертичными отложениями в западной и центральной частях антеклизы. При медленной инфильтрации кислыми поверхностными водами, карбонат кальция замещается кремнезёмом. Одновременно с этим происходит разрушение кристаллических структур минералов, неустойчивых в кислой среде.

Заключение: По стратиграфическим несогласиям и минеральным ассоциациям, подтверждены, выделенные ранее три эпохи корообразования. С рассмотренными КВ связан ряд полезных ископаемых. К ним относятся микроэлементы пород хоперского горизонта, керамические глины и мономинеральные кварцевые пески олигоцен-миоценового возраста. Но наиболее ценным является цеолит-кремнистое сырьё, которое используется во многих отраслях народного хозяйства.
\end{abstract}

Ключевые слова: Воронежская антеклиза, кайнозой, коры выветривания.

\footnotetext{
Д Дмитриев Дмитрий Анатольевич, E-mail: dmitgeol@yandex.ru 
Для цитирования: Дмитриев Д. А., Жабин А. В., Свиридов В. А. Эпохи корообразования в кайнозое Воронежской антеклизы // Вестник Воронежского государственного университета. Серия: Геология. 2020. №1. C.109-115. DOI: https://doi.org/10.17308/geology. $2020.1 / 2519$

\section{Введение}

Работами А. Д. Савко $[1,2]$ в истории кайнозоя Воронежской антеклизы, по корам выветривания (КВ) на верхнемеловых карбонатных и коррелятных песчано-глинистых кайнозойских породах, установлены три эпохи корообразования, приуроченные к перерывам в осадконакоплении - палеоценовая, олигоценмиоценовая и позднечетвертичная.

Коры выветривания, на легко разлагаемых известковых отложениях, визуально легко различаются в разрезах, так как представляют в разной степени преобразованный их нерастворимый остаток, количество которого связано с типом пород, наибольшее в мергелях, наименьшее в чистых мелах. Процессы выветривания песчано-глинистых пород, которые сами часто являются «зрелыми» образованиями при размыве КВ, в разрезах выявляются достаточно трудно. Тем не менее, их обнаружение и фиксация производится по коррелятным осадкам, обычно представленных каолиновыми глинами и кварцевыми песками континентальных фаций. Мощности сохранившихся кор выветривания зависят от многих факторов. В первую очередь, от интенсивности эрозионных процессов, как во время корообразования, так и в последующие эпохи. Не последнюю роль играет и скорость разложения коренных пород, зависящая от климата, рельефа поверхности, типа пород и др.

\section{Результаты исследований и их обсуждение}

Палеоценовая эпоха представлена образованиями хоперского горизонта, слагающими своеобразную КВ, развитую по разновозрастным (от сеноманских до маастрихтских) породам верхнего мела, и пролювиально-делювиальными отложениями, состоящими из материала её размыва [3]. Образования горизонта распространены в восточной и южной части территории антеклизы, на остальной площади они были размыты в неогеновое время. Эта КВ линейноплощадного типа, залегает на неровной закарстованной поверхности мел-мергельного субстрата, реже на сеноманских глауконит-кварцевых песках. Перекрывается верхнепалеоценовыми алевро-песчано-глинистыми отложениями. Время её формирования - ранний-средний палеоцен (около 3 млн лет). Мощности этой КВ резко меняются от 0.5 до 12 м даже на небольших расстояниях и зависят как от глубины карстовых проявлений на тех участках, на которых она развита, так и, в региональном плане, от состава материнских пород. Наибольшая её мощность отмечается на сантонских мергелях.

Обычно эта КВ в своём основании сохраняет текстуры и близкий минеральный состав материнских пород, светлую окраску с желтоватыми и бурыми налётами оксидов железа. Выше по разрезу постепенно переходит в бесструктурные охристые образования.

В сеноманских песках, за счёт разложения глауконита, выделяется значительное количество оксидов железа, окрашивающих породу в бурый цвет и в различной степени цементирующих её. При выветривании губкового горизонта сантонского возраста на юго-востоке антеклизы коренная порода обогащается дисперсным фосфатным материалом, с образованием буровато-серых желваков фосфоритов. Мергельные породы и мел преобразуются в глины, часто окремнённые, в верхней части в различной степени обохренные до охр. Налицо все признаки проявления гипергенных процессов, тем не менее, на начальных этапах изучения отложений хоперского горизонта, они трактовались как преобразованные осадки озёр, развитых на данной территории на рубеже верхнего мела и палеогена. Хотя полностью исключить данный вариант для всей площади развития кор выветривания не совсем правильно. Наверняка, на отдельных участках значительной по размерам территории Воронежской антеклизы, существовали понижения, заполненные водой, в которых шло осаждение переотложенного материала из окружающих их кор выветривания.

Результаты изучения КВ хопёрского горизонта показывают, что наиболее представительные данные для понимания особенностей её генезиса и условий, в которых проходило корообразование принадлежит рентгеновским методам анализа. В основании многих изученных разрезов глинистая часть пород представлена монтмориллонитом, иллитом и клиноптиллолитом, отвечая составу коренных отложений. Особенно это характерно для карбонатных верхнемеловых пород. Выше по разрезу, наряду с уменьшением количеств перечисленных минералов, появляются оксиды и гидроксиды железа (гетит, гидрогетит, гематит) и кремния (опал, халцедон). В верхней части превалирует каолинит и гидроксиды железа.

Формирование хоперского горизонта происходило в условиях теплого и влажного субтропического климата (не исключено, что и тропического, на что указывает наличие гиббсита в некоторых разрезах). При этом формировались относительно неглубокие карстовые полости, свидетельствующие о невысоком стоянии территории и близости водоносных горизонтов. Уже после образования, КВ подвергалась эпигенетическим процессам инфильтрации, даже через толщу каневских и бучакских песков палеогена, что привело к появлению таких минералов как галлуазит, алунит, аллофан. Химическими анализами в КВ установлены повышенные количества микроэлементов [3].

Олигоцен-миоиеновая эпоха выявлена по «зрелым» коррелятным породам в верхах олигоцена и низах миоцена, представленных континентальной шапкинской толщей, являющейся, в некоторой степени, аналогом полтавской серии. В ней маломощные линзы озерных глин среди мономинеральных кварцевых песков представлены каолинитовыми и иллит-каоли- 
нитовыми разновидностями. Только в пределах югозападной части Белгородской области они могут иметь монтмориллонит-каолинит-иллитовый состав. Так на Краснояружском месторождении керамических глин, мощностью 7-10 м, они, в нижней части разреза, серые разных оттенков, содержат железистые вишнево-красные конкреции. В составе глинистой компоненты превалирует каолинит. Суммарное содержание в ней монтмориллонита и иллита составляет не более 20\%. Выше по разрезу цвет глин постепенно меняется на бледно-желтовато-зелёный. В их глинистой составляющей начинает преобладать монтмориллонит, количество которого в кровле пласта достигает $80 \%$. В целом, порода алевритистая до песчанистой. Иногда в ней присутствуют катуны запесоченных глин.

В восточной части антеклизы глинисто-песчаные красноцветные породы континентальной шапкинской толщи с резким несогласием залегают на эоценовых и олигоценовых отложениях. Здесь, распределения глинистых минералов в разрезах аналогичны, рассмотренным на её юго-западе. Глинистая составляющая нижней части толщи преимущественно каолинитовая с незначительной примесью монтмориллонита и иллита (рис. 1). Выше по разрезам увеличиваются содержания монтмориллонита, с уменьшением количеств каолинита. Иногда, в глинистой составляющей пород кровли шапкинских отложений отмечаются незначительные проявления цеолитов.

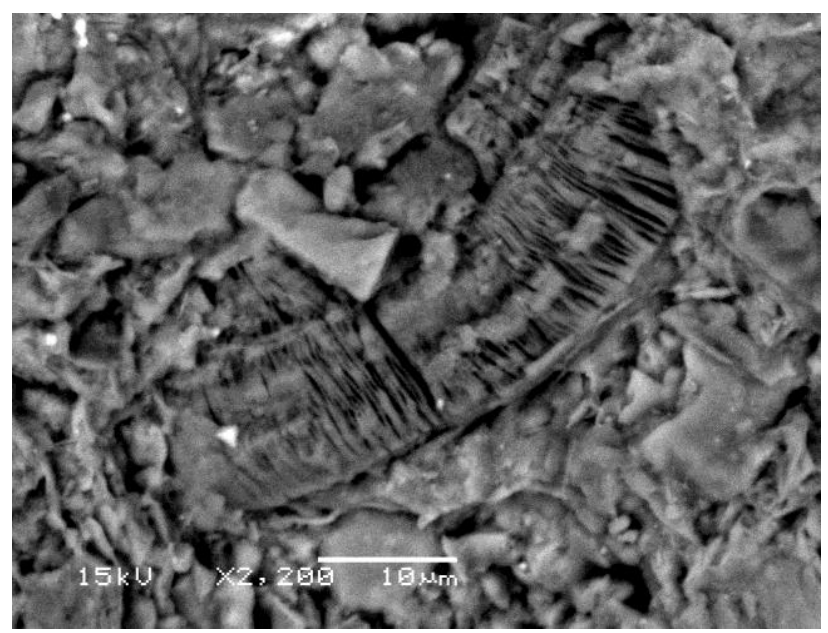

Рис. 1. Вермикулитообразная форма каолинита из коры выветривания олигоцен-миоценовых глинистых пород. Кантемировский район, Воронежская область. СЭМ.

[Fig. 1. The vermiculite-like form of kaolinite from the weathering crust of Oligocene-Miocene clay rocks. Kantemirovsky district, Voronezh region. SEM.]

При анализе полученных результатов выявляется некоторый парадокс, связанный с распределением ассоциаций глинистых минералов в рассмотренных разрезах. Казалось бы, что в их нижних частях в глинистой фракции должен превалировать монтмориллонит, а в верхних - каолинит. Здесь же всё наоборот. Поэтому мы полностью согласны с А. Д. Савко, первым высказывавшим соображения об образовании отложений шапкинской толщи. По его мнению, их формирование связано с переотложением материала кор выветривания, развитых на глинах киевского времени. Поэтому, каолинит, из размываемых в первую очередь верхних частей КВ, входил в состав осадка низов шапкинских отложений. По меpe размыва КВ поступление каолинита в осадок уменьшалось с увеличением монтмориллонитовой составляющей. Следы цеолитов в породах кровли шапкинской толщи указывают на размыв не только кор, но и коренных киевских глин, содержащих эти минералы. Следовательно, рассматриваемые отложения представляют как бы перевернутый разрез КВ.

Гипергенные процессы во время рассматриваемой эпохи начались после регрессии палеогенового моря, когда на всей площади антеклизы начала формироваться денудационная равнина. Установившийся континентальный режим по сравнению с таковым в палеогене, был менее благоприятным для выветривания из-за меньших температур и влажности, что выразилось в сокращении мощности элювия.

$B$ позднечетвертичную эпоху на рассматриваемой территории формировался современный рельеф в условиях умеренного климата. На легко разлагающихся мел-мергельных породах образовалась своеобразная кремнистая КВ, широко развитая под четвертичными отложениями в западной и центральной частях антеклизы $[2,4,5]$. Она приурочена к водораздельным участкам, где её мощности уменьшаются в сторону склонов, разделенных балками и оврагами. КВ сложена опоковидной карбонатно-кремнистоглинистой породой серовато-белого цвета. Контакт с материнскими образованиями постепенный, устанавливаемый по изменению минерального состава карбонатных отложений верхнего мела. Количество карбоната кальция, из которого состоят обломки кокколитофорид, основного материала мел-мергельных пород, уменьшается снизу вверх от 90 до 40\%. Содержания тонкодисперсного цеолито-глинисто-кремнистого вещества возрастают в том же направлении до 50\%. Обломочный алевритовый материал составляет от первых до $10 \%$ и представлен, в основном, обломками кварца, со следами химического выщелачивания, которые крайне неравномерно распределены в основной массе пород. Процентное соотношение карбоната кальция и нерастворимого остатка материала данной КВ не только отражает вещественный состав, но и обуславливает её физико-химические и технологические свойства.

Исследование нерастворимого остатка показало на присутствие в нём широкого набора минеральных форм. Основными из них являются цеолиты, кремнистые и глинистые минералы. Первые из перечисленных представлены клиноптиллолитом и гейландитом. Их образование проходит в щелочной среде, при $\mathrm{pH}$ более 9, но для клиноптиллолита требуется повышенное количество кремнезёма. 
Кремнистые минералы представлены кристобалитом, тридимитом и опалом. Последний из перечисленных является крайне неустойчивым в экзогенных условиях минеральным образованием. Он очень быстро теряет воду, количество которой может исчисляться десятками процентов и переходит в кристаллическое состояние. Поэтому нахождение его в нерастворимом остатке данной коры выветривания в количестве до 5\%, лишний раз подтверждает её молодой возраст. На электронномикроскопических снимках наблюдается в виде глобул с гладкой поверхностью (рис. 2). Кристобалит и тридимит, встречаемые в осадочных отложениях, по мнению некоторых исследователей [6], являются единой минеральной формой. Тем более что значения их рефлексов в рентгенометрических базах, даны для их аналогов образованных в эндогенных условиях. На электронномикроскопических снимках (рис. 3) наблюдаются в виде шаровидных форм с выступающими из их поверхности рёбрами. Количество этих (или этого) минеральных компонентов изменяется в широких пределах от первых процентов до $40 \%$.

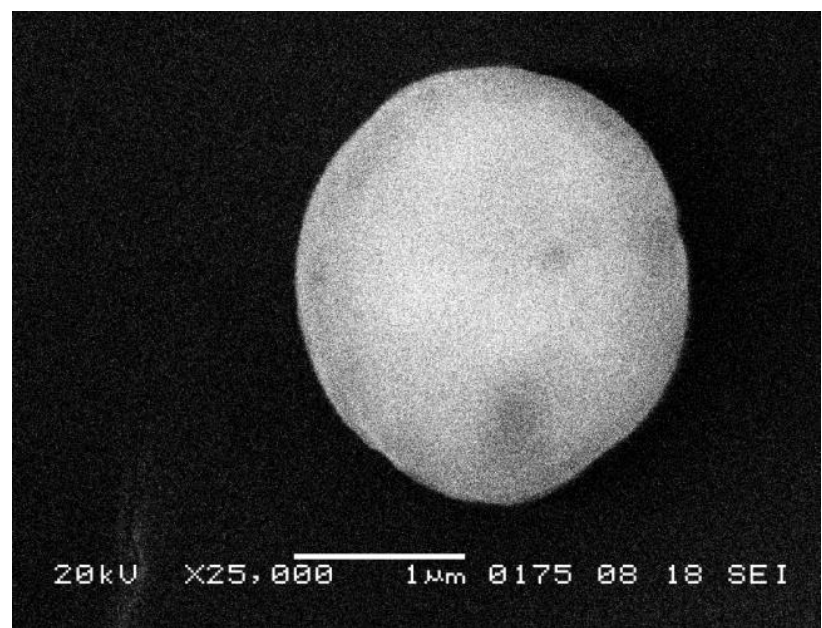

Рис. 2. Глобула опала из позднечетвертичной коры выветривания по верхнемеловым породам. Семилукский район, Воронежская область. СЭМ.

[Fig. 2. Globule opal from the Late Quaternary weathering crust along the Upper Cretaceous rocks. Semiluksky district, Voronezh region. SEM.]

Глинистые минералы являются неотъемлемой составной частью коренных мел-мергельных пород. В зависимости от степени выщелачивания карбоната кальция и замещением его кремнезёмом, их количество в нерастворимом остатке колеблется от 15 до $65 \%$. Представлены они глауконитом, иллитом и монтмориллонитом. Содержание первого, из перечисленных, очень незначительно, составляя не более $1 \%$. Встречается в виде округлых, почковидных зёрен светло-зелёного цвета. Их размеры менее 0,1 мм. На электронномикроскопических снимках (рис. 4) внутренней части зёрен выглядит в виде пластинчатых чешуек, направленных в разные стороны из многих центров. По нашему мнению, глауконит образуется

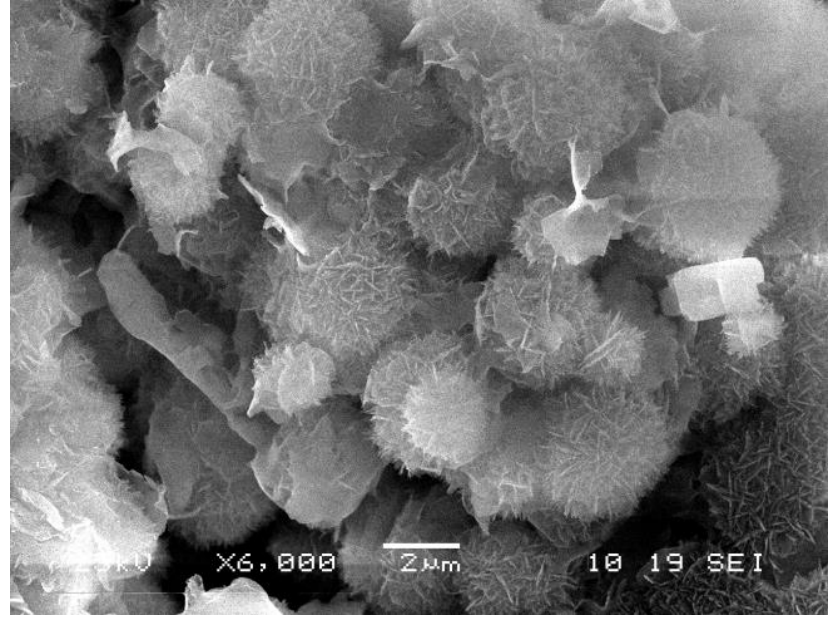

Рис. 3. Тридимит-кристобалитовые глобули из позднечетвертичной коры выветривания по верхнемеловым породам. Касторненский район, Курская область. СЭМ.

[Fig. 3. Tridymite-cristobalite globules from the Late Quaternary weathering crust along the Upper Cretaceous rocks. Kastornensky district, Kursk region. SEM].

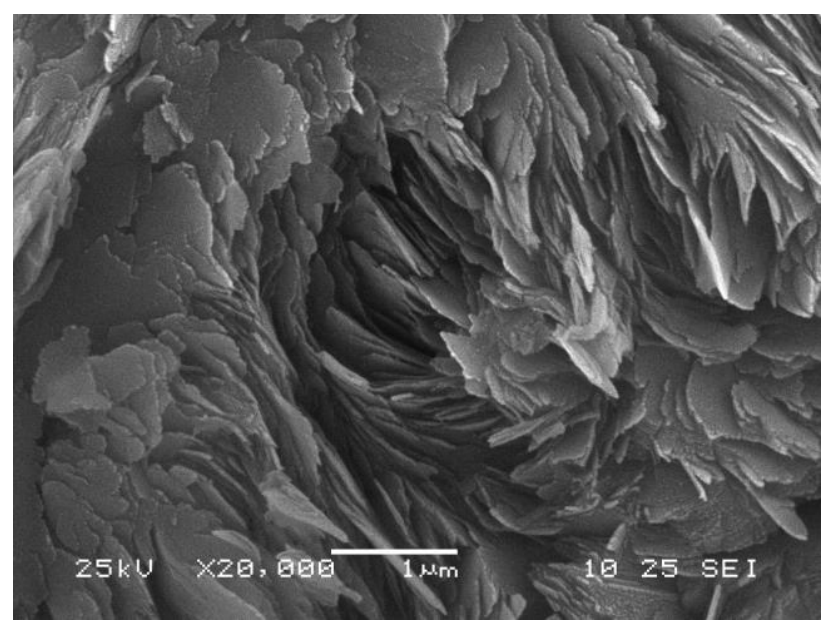

Рис. 4. Радиально-лучистое строение зерна глауконита с одним центром роста. Кора выветривания по верхнемеловым породам. Нижнедевицкий район, Воронежская область. СЭМ.

[Fig. 4. Radial-radiant grain structure of glauconite with one growth center. Weathering crust over Upper Cretaceous rocks. Nizhnedevitsky district, Voronezh region. SEM.]

при деструкционно-эпитаксиальном преобразовании силикатных обломков и росту на их поверхности новых слоистых минералов [7].

Содержание иллита варьирует в широких пределах от 10 до 30\%. Характерно уменьшение количества этого минерала снизу вверх по разрезу, что связано, вероятно, с потерей калия в кислотной среде верхней части КВ. С повышенной кислотностью связано и незначительные (до 5\%), до полного отсутствия, количества монтмориллонита.

Минералы примеси составляют от 0.5 до $3 \%$. Представлены удлинёнными чешуйками мусковита, оксидами железа в виде пятнистых выделений за счёт окисления сульфидов и частично глауконита. Нередки 
органические остатки. Это радиолярии, спикулы губок, зубы и чешуя рыб, копролиты.

Формирование рассматриваемых КВ рассматривается следующим образом. Поверхностная вода имеет значение $\mathrm{pH}$ около 7. Но, за счёт разложения гумусового вещества (в первую очередь), растворения в ней $\mathrm{CO}_{2}$ и компонентов некоторых минералов, $\mathrm{pH}$ понижается до 4-5 с образованием каолинита в условиях субтропического климата. При повышении среднесуточных температур в тропическом климате начинает выноситься кремнезём, и образуются минералы глинозёма. В нижней части кор выветривания, при условии слабой расчленённости рельефа и близости грунтовых вод, накапливаются щелочные и щёлочноземельные элементы, что приводит к повышению $\mathrm{pH}$ до 8-9 и генезису монтмориллонита.

В позднечетвертичную эпоху выветривание проходило в условиях умеренного климата, что наложило отпечаток на процессы корообразования. Разложение карбонатных пород может проходить двумя путями. В первом случае, при быстром разрушении их поверхности, развиваются карстовые процессы. Во втором при медленной инфильтрации кислыми поверхностными водами, карбонат кальция замещается кремнезёмом. Одновременно с этим происходит разрушение кристаллических структур минералов, неустойчивых в кислой среде.

Освободившийся кальций и щелочные элементы накапливались в нижних горизонтах КВ, увеличивая щёлочность среды, а кремнезём приобретал подвижность. В участках приближения подземных вод к зонам разгрузки, где понижалось $\mathrm{pH}, \mathrm{SiO}_{2}$ выпадал, образуя твердую фазу. Вначале она представлена аморфным опалом, который затем переходит в тридимит и кристобалит, халцедон.

С рассмотренными КВ и образованными за счет их размыва отложениями связан ряд полезных ископаемых. К ним относятся микроэлементы пород хоперского горизонта, керамические глины и мономине- ральные кварцевые пески олигоцен-миоценового возраста. Но наиболее ценным является цеолит-кремнистое сырьё, которое используется во многих отраслях народного хозяйства, в том числе для мелиорации почв, производства тепличных субстратов, добавок в корма, вяжущих стройматериалов. Кроме того, они применяются для обезвреживания отходящих газов и жидких стоков, дезактивации отходов производства, водоподготовки и т.д.

Конфликт интересов: Автор декларирует отсутствие явных и потенциальных конфликтов интересов, связанных с публикацией настоящей статьи.

\section{ЛИТЕРАТУРА}

1. Савко А. Д. Эпохи корообразования в истории Воронежской антеклизы. Воронеж: Изд-во ВГУ, 1979. 120 с.

2. Чигарев А. Г., Савко А. Д. Кайнозойская кора выветривания Старооскольского района КМА. Труды научноисследовательского института геологии Воронеж. гос. унта. Вып. 63. Воронеж: Изд-во Воронеж. ун-та, 2011. 101 с.

3. Аскоченский Б. В., Семенов В. П. Кора выветривания карбонатных пород верхнего мела Воронежской антеклизы. Воронеж: Изд-во ВГУ, 1973. 175 с.

4. Дмитриев Д. А., Савко А. Д., Жабин А. В. Сантонские отложения правобережья среднего течения реки Дон. Труды научно-исследовательского института геологии Воронеж. гос. ун-та. Вып. 21. Воронеж: Изд-во Воронеж. ун-та, 2004. $104 \mathrm{c}$.

5. Савко А. Д., Свиридов В. А. Позднекайнозойская кора выветривания междуречья рек Олым, Ведуга и Девица (Курская и Воронежская области) // Вестник Воронежского государственного университета. Серия: Геология. 2015. № 4. C. $28-37$.

6. Бардаши Д., Конди Й., Рапп-Шин Ш., Толнаи В. Кристобаллит в бат-келловейских радиоляритах гор Баконь // Проблемы геохимии. М.: 1965. $690 \mathrm{c}$.

7. Жабин А. В. Минеральный состав глауконитовых сферолитов в верхнемеловых и палеогеновых отложениях Воронежской антеклизы. // Вестник Воронежского государственного университета. Серия: Геология. 2000. №5(10). С. $58-63$. 


\title{
Epochs of weathering crust formation in the Cenozoic of the Voronezh Anteclise
}

\author{
(c) 2020 D. A. Dmitriev ${ }^{\bowtie}$, A. V. Zhabin, V. A. Sviridov \\ ${ }^{I}$ Voronezh State University, 1 Universitetskaya pl., Voronezh 394018, Russian Federation
}

\begin{abstract}
Introduction: Cenozoic formations of the Voronezh Anteclise, with a depth of up to $100 \mathrm{~m}$, are accessible for research in the outcrops on the slopes of river valleys, gulches, ravines, and the holes of shallow wells. They are represented by sandy clay rocks of various genesis. The Paleogene is characterized by marine deposits, while the Neogene is characterized by alluvial and lacustrine deposits. Quaternary formations, which are the most representative based on the genetic types of rocks, are composed of alluvial, river terrace, glacial deposits, and cover loams. In the history of the Cenozoic of the Voronezh Anteclise, three epochs of crust formation are distinguished: the Paleocene, Oligocene-Miocene, and Late Quaternary. The deposits of each epoch are associated with certain minerals. The most valuable siliceous-zeolite raw materials are confined to the last epoch. The article discusses the relationship of climate, surface topography, type of rocks with the mineral composition of weathering crust. A genetic interpretation of the formation of minerals in hypergenic processes is presented.

Methodology: The study of the mineral composition of the rocks, which constitute both the weathering crust (WC) and the host sediments, was carried out by X-ray diffraction and electron microscopic analysis methods.

Results and discussion: The Paleocene era is represented by a weathering crust of a linear-areal type, deposited on the carstified surface of the Upper Cretaceous deposits. Its formation occurred under warm and humid subtropical climate (it can't be excluded that the climate was tropical, based on the presence of gibbsite in some sections). The Oligocene-Miocene era was detected by "mature" correlate rocks in the upper Oligocene and lower Miocene, represented by the continental Shapkinskaya sequence. The kaolinite composition of its lower part and montmorillonite composition of the upper part, represent an inverted section of the weathering crust. Its formation took place under a climate less favourable for weathering due to lower temperatures and humidity, which resulted in a reduction of the thickness of the eluvium. In the Late Quaternary era, a modern relief was formed on the studied territory under temperate climate. The peculiar siliceous WC, widely developed under the Quaternary deposits in the western and central parts of anteclise, was formed on easily decomposed chalk-marl rocks. Due to the slow infiltration of acidic surface waters, calcium carbonate was replaced by silica. At the same time, the crystal structures of minerals were destroyed as they are unstable in an acidic environment.

Conclusions: According to stratigraphic nonconformities and mineral associations, three epochs of weathering crust formation that had been previous identified were confirmed. Various minerals are associated with the considered WC. These minerals include trace minerals of rocks the Khopersky horizon, ceramic clays, and monomineral quartz sands of the Oligocene-Miocene age. The most valuable is zeolite-siliceous raw materials, which are used in many sectors of the national economy.
\end{abstract}

Keywords: Voronezh Anteclise, Cenozoic, weathering crust.

The content is available under Creative Commons Attribution 4.0 License.

\footnotetext{
${ }^{\circledR}$ Dmitriy A. Dmitriev, E-mail: dmitgeol@yandex.ru
} 
For citation: Dmitriev D. A., Zhabin A. V., Sviridov V. A. Epochs of weathering crust formation in the Cenozoic of the Voronezh Anteclise. Vestnik Voronezhskogo gosudarstvennogo universiteta. Seriya: Geologiya = Proceedings of Voronezh State University. Series: Geology,. 2020. No. 1 pp.109-115. DOI: https://doi.org/10.17308/geo$\operatorname{logy} .2020 .1 / 2519$

Conflict of interests: The authors declare the absence of obvious and potential conflicts of interest related to the publication of this article.

\section{REFERENCES}

1. Savko A.D. Jepohi koroobrazovanija v istorii Voronezhskoj anteklizy [The epochs of the formation of weathering crust in the history of the Voronezh anteclise]. Voronezh, VSU Publ., 1979, 120 p. (In Russ.)

2. Chigarev A. G., Savko A. D. Kainozoiskaya kora vyvetrivaniya Starooskol'skogo raiona KMA [Cenozoic weathering crust of the Stary Oskol region of KMA]. Trudy Nauchnoissledovatel'skogo Instituta Geologii [The work of the Research Institute of Geology], Voronezh, VSU Publ., vol. 63, 2011, 101 p. (In Russ.)

3. Askochenskii B. V., Semenov V.P. Kora vyvetrivaniya karbonatnykh porod verkhnego mela Voronezhskoi anteklizy [Weathering crust of carbonate rocks of the Upper Cretaceous of the Voronezh anteclise]. Voronezh, VSU Publ., 1973, 175 p. (In Russ.)

4. Dmitriev D. A., Savko A. D., Zhabin A. V. Santonskie otlozheniya pravoberezh'ya srednego techeniya reki Don [Santonian deposits on the right bank of the middle reaches of the Don River]. Trudy Nauchno-issledovatel'skogo Instituta Geologii [The work of the Research Institute of Geology], Voronezh, VSU Publ., vol. 21, 2004, 104 p. (In Russ.)

5. Savko A.D., Sviridov V. A. Late Cenozoic weathering crust between the rivers Olym, Veduga and Devitsa (Kursk and Voronezh regions). Vestnik Voronezhskogo gosudarstvennogo universiteta. Seriya: Geologiya = Proceedings of Voronezh State University. Series: Geology, 2015, no. 4, pp. 28-37. (In Russ.)

6. Bardashi D., Kondi I., Rapp-Shin Sh., Tolnai V. Kristoballit $v$ bat-kelloveiskikh radiolyaritakh gor Bakon' [Cristoballit in the Bat-Callovian radiolarites of the Bacon Mountains]. Problemy geokhimii [Problems of geochemistry], Moscow, 1965, 690 p. (In Russ.)

7. Zhabin A.V. Mineral composition of glauconite spherulites in the Upper Cretaceous and Paleogene sediments of the Voronezh anteclise. Vestnik Voronezhskogo gosudarstvennogo universiteta. Seriya: Geologiya $=$ Proceedings of Voronezh State University. Series: Geology, 2000, no. 5, pp. 58-63. (In Russ.)

\footnotetext{
Дмитриев Дмитрий Анатольевич - к.г.-м.н., доцент кафедры исторической геологии и палеонтологии, Воронежский государственный университет, Воронеж, Российская Федерация; E-mail: dmitgeol@ yandex.ru; ORCID http://orcid.org/0000-0003-1986-1241.

Жабин Александр Васильевич - к.г.-м.н., доцент кафедры общей геологии и геодинамики, Воронежский государственный университет, Воронеж, Российская Федерация; E-mail: zhabin01@gmail.com; ORCID http://orcid.org/0000-0002-3844-6302.

Свиридов Владислав Алексеевич - аспирант, Воронежский государственный университет, Воронеж, Российская Федерация; E-mail: Junior-vlad@ mail.ru;

ORCID https://orcid.org/0000-0002-6530-7922
}

Авторы прочитали и одобрили окончательный вариант рукописи.
Dmitriy A. Dmitriev - PhD in Geol-Min., Associate Professor, Department of Historical Geology and Paleontology, Voronezh State University, Voronezh, Russian Federation; E-mail: dmitgeol@yandex.ru; ORCID http://orcid.org/0000-0003-1986-1241.

Aleksandr V. Zhabin - PhD in Geol-Min., Associate Professor, Department of the General Geology and Geodynamics, Voronezh State University, Voronezh, Russian Federation;

E-mail: zhabin01@gmail.com; ORCID http://orcid.org/0000-0002-3844-6302.

Vladislav A. Sviridov - postgraduate student, Voronezh State University, Voronezh, Russian Federation;

E-mail: Junior-vlad@mail.ru; ORCID https://orcid.org/0000-0002-6530-7922

All authors have read and approved the final manuscript. 